\title{
Sedimentary processes may cause fluctuations of tidewater glaciers
}

\author{
Richard B. Alley \\ Earth System Science Center and Department of Geosciences, The Pennsylvania State University, \\ University Park, PA 16802, U.S.A.
}

\begin{abstract}
A temperate glacier ending in water advances by depositing a moraine shoal, which "dams" tidewater calving, and then recycling this shoal in conveyor-belt fashion. A simple model suggests that conveyor-belt recycling of the shoal must continue until calving stops and all ice flux is removed by surface ablation, or until the glacier retreats rapidly from the shoal; retreat can occur without external forcing if the glacier advances into deepening water and if sediment recycling is rapid compared to supply of new sediment to the moraine shoal.
\end{abstract}

\section{INTRODUCTION}

The behavior of temperate, tidewater glaciers (i.e. calving icebergs into a marginal water body) is affected strongly by their sedimentary systems (Post, 1975; Meier and Post, 1987). Subglacial deformation, stream (subglacial, supraglacial and ice-marginal) and other processes usually deliver sediment to the fronts of such glaciers more rapidly than it is removed by marine or lacustrine processes (Powell, 1984; Anderson and Molnia, 1989; Meier, 1989), forming deposits called moraine shoals.

The calving-front positions of temperate tidewater glaciers are observed to go through a cycle of slow advance (typically $\approx 30 \mathrm{ma}^{-1}$ ) followed by rapid retreat or collapse (typically $\approx 1000 \mathrm{~m} \mathrm{a}^{-1}$ ), with a large amplitude (typically $\approx 30 \mathrm{~km}$ ) (Post, 1975 ; Meier and Post, 1987). Advance occurs behind the moraine shoal, which is eroded on the up-glacier side with deposition on the down-glacier side, causing shoal advance through "conveyor-belt" recycling (Post, 1975; Meier and Post, 1987). Quantitative observations of a suite of tidewater glaciers in Alaska, U.S.A., dominated by retreating or nearly steady glaciers, shows that the rate of iceberg calving increases linearly with the water depth at the calving front (Brown and others, 1982). During advance, these glaciers move into water deep enough to cause the calving velocity to exceed the ice-flow velocity. Advance is possible because the moraine shoals reduce the water depth and restrict calving. The advance/retreat cycle is asymmetric because advance occurs at the (slow) rate of moraine-shoal recycling, but if the ice retreats from the shoal into deeper water, calving increases and retreat occurs rapidly (Post, 1975; Meier and Post, 1987).

During much of the advance phase, such glaciers are relatively insensitive to climatic changes (Post, 1975; Meier and Post, 1987). This suggests that the correlation between water depth and iceberg calving observed by Brown and others (1982) for primarily retreating and stable glaciers defines a minimum rate of iceberg calving (Meier and Post, 1987). During advance, if the ice flux exceeds the calving flux of Brown and others (1982), the "excess" ice will thin as it passes over the moraine shoal and will begin to float in deeper water beyond. If this excess ice were cold, it could form an ice shelf. However, temperate glaciers are never observed to float, except locally and transiently, presumably because abundant englacial water makes them too weak to prevent calving in the absence of restraint from basal shear stress (Meier and Post, 1987). Thus, any excess temperate ice passing over a moraine shoal will calve when it approaches flotation.

If calving is removing excess ice, then small, climatically induced reductions in ice flux will affect this excess ice but not the well-grounded ice behind the shoal. Such a glacier is climatically insensitive; that is, it can advance during reductions in snowfall or increases in melting. If a marginal advance lengthens the ablation zone and reduces the ice flux close to the minimum calving flux, then the glacier will become climatically sensitive: a small climate change could reduce ice flux below calving flux, causing retreat from the moraine shoal into deeper water, increased calving, and rapid retreat (Post, 1975; Meier and Post, 1987).

If climatic change were the only way to trigger retreat, then each glacier retreat would record a reduction in mass balance (although a glacier might advance through several such reductions before retreating) and the marginal fluctuations of a suite of glaciers in an area might record most or all decreases in regional glacier mass balance. However, it remains possible that nonclimatic causes could trigger retreats. For example, a large earthquake could cause slumping and reduction in height of a moraine shoal, increasing the calving above the ice flux and triggering collapse.

Here, I suggest that sedimentary processes may cause 
rapid marginal retreats of temperature tidewater glaciers in the absence of external forcings. I present a theoretical construct that is not supported by any direct observational evidence; however, the arguments appear sufficiently plausible to urge caution in any attempt to use the fluctuations of temperate tidewater glaciers as paleoclimatic indicators.

\section{MODEL}

Extensive subglacial observations are available for only one temperate calving glacier: Columbia Glacier in Alaska, U.S.A. (Fahnestock and Humphrey, 1988; Meier, 1989). There, at one site a few kilometers up-glacier from the terminus, the basal stress is deforming an unconsolidated sediment bed about $0.5 \mathrm{~m}$ thick with water pressure within about 1 bar or less of the ice-overburden pressure, overlying more consolidated material (bedrock ?). Similar water pressures and a thinner debris layer were detected at a second site beneath Columbia Glacier, but no measurements were made to learn whether or not that debris was deforming (Fahnestock and Humphrey, 1988; Meier, 1989). The basal shear stress is approximately 1 bar at the observational sites, and changes little passing down-glacier from these sites onto the moraine shoal (Bindschadler, 1983), which is probably composed of unlithified sediments. Moving down-glacier from the observation sites onto the moraine shoal, the basal water pressure probably increases relative to the overburden

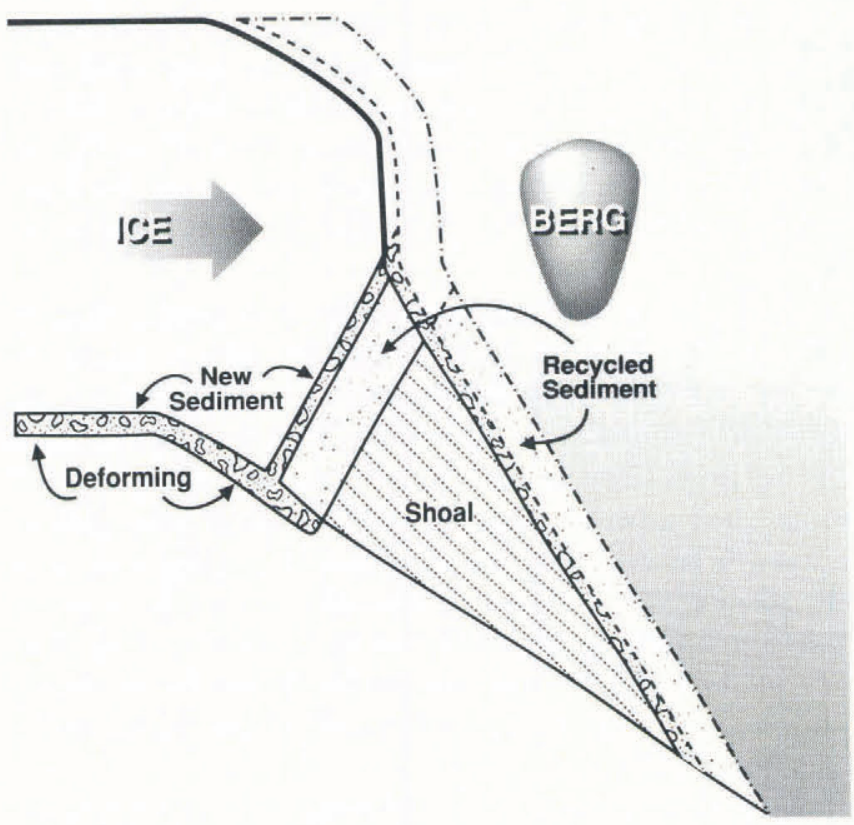

Fig. 1. Cartoon of moraine-shoal model. Glacier calves bergs into marginal water. At some time, the shoal is at the position shown by the solid line. A thin deforming bed (circleand-dot pattern) supplies new material to the shoal, building it up and out and allowing ice advance (dashed lines). The deforming bed thickens onto the shoal, causing recycling (dotted pattern), ice advance and either upward or downward movement of the shoal top, depending on bedrock slope (dot-dash line). pressure, decreasing the strength of subglacial sediments (Bindschadler, 1983; Meier and Post, 1987).

Based on this, I assume that high water pressure and high basal shear stress on the moraine shoal of a temperate tidewater glacier allow sediment deformation that dominates sediment flux. (We know that at least some subglacial or subaerial stream transport occurs, and that such stream transport may dominate the sediment budget, so this computationally simple assumption introduces uncertainty; see below.) I assume further that the shoal erodes more easily than material beneath the body of the glacier, causing the deforming-layer thickness and total sediment flux across the shoal to exceed the thickness and sediment supply to the shoal, so that the shoal is recycled and moves forward (Fig. 1). At the same time, the shoal still serves as a "dam" to ice motion and calving, so that it must maintain normal and shear stresses on the ice to prevent rapid ice calving and catastrophic retreat.

Under these conditions, it would appear that the glacier must continue advancing at the rate of shoal recycling until the entire ice flux is removed by ablation (the velocity at the ice terminus drops to zero, so that the shoal cannot be moved forward), or until something causes retreat from the shoal. The alternative, that the glacier can stop recycling its shoal while still using it as a dam, does not seem plausible physically.

\section{Recycling rate, bed slope and stability}

Assume one-dimensional flow, with ice-marginal velocity and ice and sediment velocity and flux taken to be positive along the horizontal $x$ axis directed along the glacier towards the calving front. The sediment flux, $q_{\mathrm{s}}$, in a deforming bed can be written

$$
q_{\mathrm{s}}=\alpha h_{\mathrm{b}} u_{\mathrm{i}},
$$

where $h_{\mathrm{b}}$ is the deforming thickness, $u_{\mathrm{i}}$ is the velocity at the top of the deforming layer (and probably approximates the basal ice velocity) and $\alpha$ is a shape factor that corrects for downward decrease in sediment strain rate and probably lies between 0.1 and 0.5 (Alley, 1989).

The thickness of deforming subglacial sediments, $h_{\mathrm{b}}$, can be limited by erosion rate (if little debris is available, then the flux balances the supply for a relatively thin layer) or by downward increase in sediment strength (which is believed to increase with the difference between overburden and pore-water pressure, a difference that will increase downward if the pore water is interconnected efficiently and maintains a hydrostatic pressure gradient (Boulton and Hindmarsh, 1987; Alley, 1989)). Suppose, for the sake of illustration, that $u_{\mathrm{i}}$ and $\alpha$ are the same for the main bed of a glacier and for its moraine shoal, that $h_{\mathrm{b}}=h_{\mathrm{bo}}$ along the main bed is limited by sediment availability, and that $h_{\mathrm{b}}$ increases to its maximum value, $h_{\mathrm{b} \max }$, on the easily erodible shoal $\left(h_{\mathrm{bo}}\right.$ may be $0.1-0.5 \mathrm{~m}$ (Fahnestock and Humphrey, 1988; Meier, 1989), and $h_{\mathrm{b} \max }$ may be $5-10 \mathrm{~m}$ (MacClintock and Dreimanis, 1964; Alley, 1989)). Then the flux of sediment added to the shoal, $q_{\mathrm{b}}$ is given by

$$
q_{\mathrm{b}}=\alpha u_{\mathrm{i}} h_{\mathrm{bo}}
$$


and the flux of recycled sediment contributing to shoal migration, $q_{\mathrm{r}}$, is

$$
q_{\mathrm{r}}=\alpha u_{\mathrm{i}}\left(h_{\mathrm{bmax}}-h_{\mathrm{bo}}\right)
$$

(More accurately, $\alpha$ might decrease onto the shoal (Alley, 1989), but $u_{\mathrm{i}}$ will increase to balance ice thinning onto the shoal. These effects may more or less offset each other.)

The moraine shoal can move forward in two ways. Recycled material can be transported from its up-glacier to its down-glacier side, and new material derived from up-glacier of the shoal can be added to the down-glacier side of the shoal. The water depth over the shoal can be changed by recycling, causing shoal migration up or down a sloping bed, and through vertical build-up of the shoal from the addition of new material.

Assume that the slope angles to the horizontal on the up-glacier and down-glacier sides of the shoal are constant with positive values $\phi_{\mathrm{u}}$ and $\phi_{\mathrm{d}}$, respectively (Fig. $2)$. The glacier, the shoal and the marginal water body

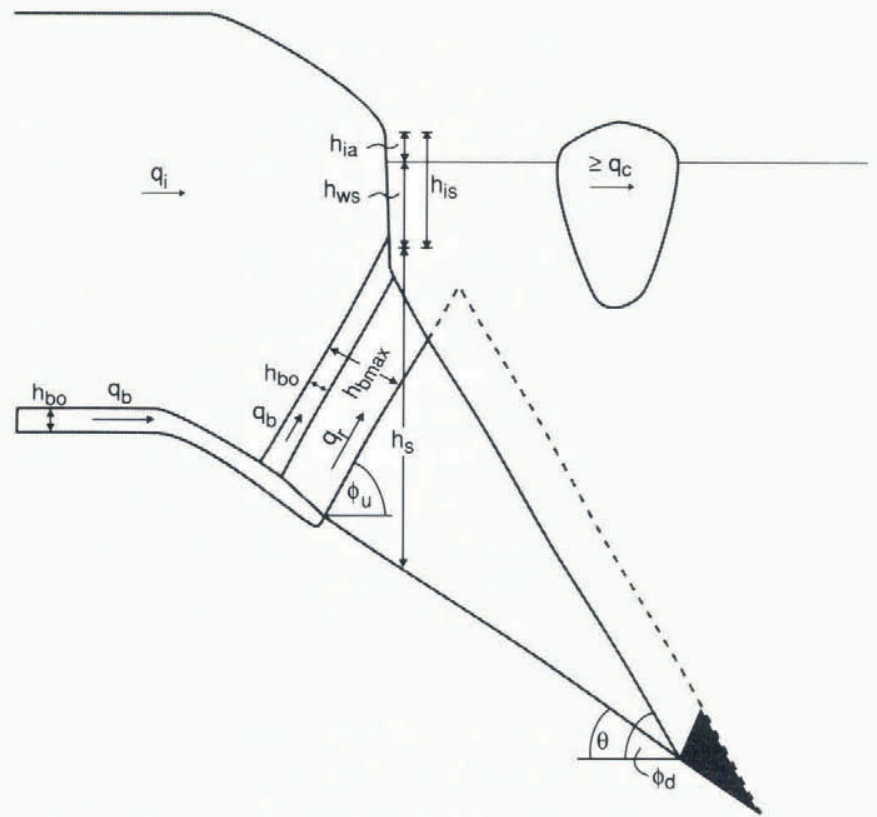

Fig. 2. Variables used in the model. The total calving height, $h_{\text {is }}$, is the sum of the water depth over the shoal, $h_{w s}$ and the ice-cliff height above the water, $h_{i a}$. Other variables are defined in the text.

rest on planar bedrock that slopes at angle $\theta$ positive for down-glacier slope, the shoal is relatively high and $\phi_{\mathrm{d}}$ does not approach $\theta$ too closely.

The geometry for estimating the shoal-advance rate from the addition of new material is shown in Figure 3. A quantity of material $q_{\mathrm{b}} \mathrm{d} t$ is deposited in time $\mathrm{d} t$, causing the shoal peak to advance by $l_{\mathrm{b}}$ through formation of the deposit outlined by dashed lines. Approximating the new deposit by the parallelogram $m n$ yields

$$
m n \sin \left(\phi_{\mathrm{u}}+\phi_{\mathrm{d}}\right)=q_{\mathrm{b}} \mathrm{d} t .
$$

From the law of sines,

$$
m=\frac{h_{\mathrm{s}} \sin (90+\theta)}{\sin \left(\phi_{\mathrm{d}}-\theta\right)}=\frac{h_{\mathrm{s}} \cos \theta}{\sin \left(\phi_{\mathrm{d}}-\theta\right)},
$$

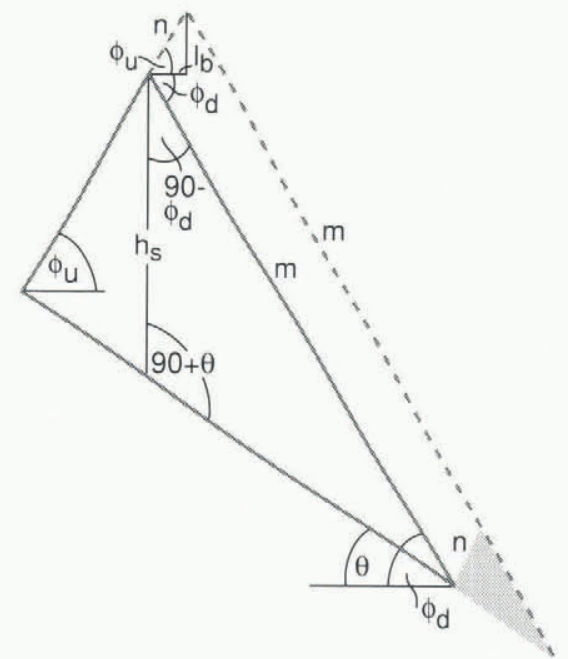

Fig. 3. Geometry for estimating moraineshoal advance from addition of new material. Approximation is in error by shaded region, which is small if assumptions in text are met.

where $h_{\mathrm{s}}$ is the shoal height, angles are in degrees, and the final expression has been simplified using a trigonometric identity. Also, inspection of Figure 3 shows

$$
n=l_{\mathrm{b}}\left(\cos \phi_{\mathrm{u}}\right)^{-1} \text {. }
$$

Substituting for $m$ and $n$ in Equation (4) from Equations (5) and (6) and solving for the advance rate, $l_{\mathrm{b}} / \mathrm{d} t$ yields

$$
\frac{l_{\mathrm{b}}}{\mathrm{d} t}=\frac{q_{\mathrm{b}} \sin \left(\phi_{\mathrm{d}}-\theta\right) \cos \phi_{\mathrm{u}}}{h_{\mathrm{s}} \cos \theta \sin \left(\phi_{\mathrm{u}}+\phi_{\mathrm{d}}\right)} .
$$

The water depth over the peak of the shoal, $h_{\mathrm{ws}}=h_{\mathrm{wo}}-$ $h_{\mathrm{s}}$, where $h_{\text {wo }}$ is the water depth there in the absence of a shoal, changes at the rate

$$
\left(\frac{\mathrm{d} h_{\mathrm{ws}}}{\mathrm{d} t}\right)_{\mathrm{b}}=-\frac{l_{\mathrm{b}}}{\mathrm{d} t} \tan \phi_{\mathrm{u}} .
$$

For sediment recycling, shoal-peak advance $l_{\mathrm{r}}$ is caused by transfer of a quantity of sediment $q_{\mathrm{r}} \mathrm{d} t$ across the peak of the shoal, which can be approximated by the parallelogram $c d$ in Figure 4. Then

$$
c d \sin \left(\phi_{\mathrm{u}}+\phi_{\mathrm{d}}\right)=q_{\mathrm{r}} \mathrm{d} t
$$

From the law of sines,

$$
c=\frac{h_{\mathrm{s}} \sin (90-\theta)}{\sin \left(\phi_{\mathrm{u}}+\theta\right)}=\frac{h_{\mathrm{s}} \cos \theta}{\sin \left(\phi_{\mathrm{u}}+\theta\right)}
$$

and

$$
d=\frac{l_{\mathrm{s}} \sin \left(\phi_{\mathrm{u}}+\theta\right)}{\sin \left(\phi_{\mathrm{u}}+\phi_{\mathrm{d}}\right)} .
$$

Here $l_{\mathrm{s}}$ is the advance distance along the bedrock, related to the horizontal advance distance of the shoal peak, and of the up-glacier edge of the shoal, $l_{\mathrm{r}}$, by

$$
l_{\mathrm{r}}=l_{\mathrm{s}} \cos \theta \text {. }
$$




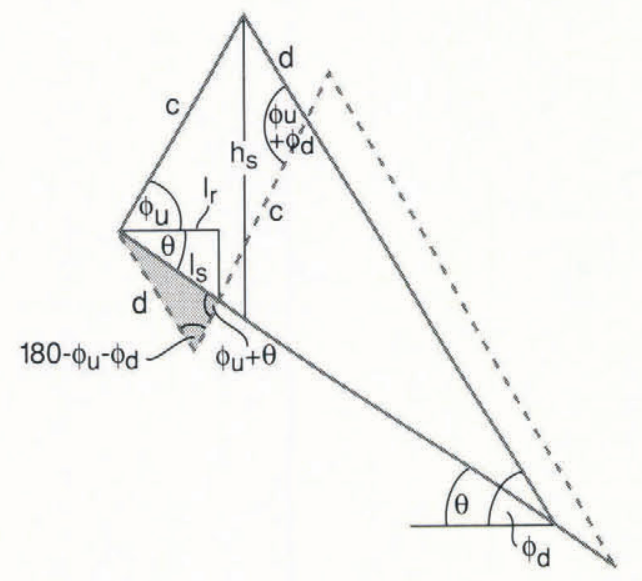

Fig. 4. Geometry for estimating moraineshoal advance from recycling of material in shoal. Approximation is in error by shaded region, which is small if assumptions in text are met.

Substituting for $c$ and $d$ in Equation (9) from Equations (10) and (11), with $l_{\mathrm{s}}$ taken from Equation (12), and solving for the advance rate, $l_{\mathrm{r}} / \mathrm{d} t$, yields

$$
\frac{l_{\mathrm{r}}}{\mathrm{d} t}=\frac{q_{\mathrm{r}}}{h_{\mathrm{s}}} .
$$

Also,

$$
\left(\frac{\mathrm{d} h_{\mathrm{ws}}}{\mathrm{d} t}\right)_{\mathrm{r}}=\frac{l_{\mathrm{r}}}{\mathrm{d} t} \tan \theta .
$$

Combining Equations (7) and (13), the shoal peak advances at the rate $\nu_{\mathrm{s}}=\left(l_{\mathrm{b}}+l_{\mathrm{r}}\right) / \mathrm{d} t$ given by

$$
\nu_{\mathrm{s}}=\frac{q_{\mathrm{b}} \sin \left(\phi_{\mathrm{d}}-\theta\right) \cos \phi_{\mathrm{u}}}{h_{\mathrm{s}} \cos \theta \sin \left(\phi_{\mathrm{u}}+\phi_{\mathrm{d}}\right)}+\frac{q_{\mathrm{r}}}{h_{\mathrm{s}}}
$$

and combining Equations (8) and (14), the water depth changes at the rate

$$
\frac{\mathrm{d} h_{\mathrm{ws}}}{\mathrm{d} t}=-\frac{q_{\mathrm{b}} \sin \left(\phi_{\mathrm{d}}-\theta\right) \cos \phi_{\mathrm{u}} \tan \phi_{\mathrm{u}}}{h_{\mathrm{s}} \cos \theta \sin \left(\phi_{\mathrm{u}}+\phi_{\mathrm{d}}\right)}+\frac{q_{\mathrm{r}} \tan \theta}{h_{\mathrm{s}}} .
$$

If a flux of sediment $q_{\mathrm{b}}$ has been added to a shoal, initially of zero volume over time $t$, then the area of the shoal in a cross-section along flow is simply $q_{\mathrm{b}} t$. With the area and all angles known, direct application of trigonometry yields the shoal altitude, $h_{\mathrm{s}}$ (Fig. 2), as

$$
h_{\mathrm{s}}=\left(2 q_{\mathrm{b}} t\left(\frac{\cos \phi_{\mathrm{u}} \cos \theta}{\sin \left(\phi_{\mathrm{u}}+\theta\right)}+\frac{\cos \phi_{\mathrm{d}} \cos \theta}{\sin \left(\phi_{\mathrm{d}}-\theta\right)}\right)^{-1}\right)^{\frac{1}{2}} .
$$

The ice flux to the ice front is $q_{\mathrm{i}}$, given by

$$
q_{\mathrm{i}}=q_{\mathrm{io}}+\dot{b} l_{\mathrm{a}},
$$

where $q_{\text {io }}$ is ice flux to the ice front at its most retreated position, $l_{\mathrm{a}}$ is the length past that position to the highest point of the shoal and $\dot{b}$ is the mass balance of the ice (assumed to be independent of position, otherwise Equation (18) must be rewritten as an integral over distance) and typically is strongly negative.
The minimum calving flux, $q_{\mathrm{c}}$, is given by (Brown and others, 1982)

$$
q_{\mathrm{c}}=K h_{\mathrm{ws}} h_{\mathrm{is}},
$$

where $K$ is a constant, $K h_{\mathrm{ws}}$ is the calving velocity and $h_{\text {is }}$ is the total ice thickness, both above and below water, over the highest point of the shoal.

Equations (15) to (17), plus specified bed geometry and sediment fluxes to and across a moraine shoal, model the evolution of the shoal position and the water depth over it. The shoal position, the ice flux from up-glacier, $q_{\text {io, }}$, and the mass balance, $\dot{b}$, yield the ice flux to the shoal through Equation (18). The ice thickness, water depth and calving constant (determined empirically (Brown and others, 1982)) yield the minimum calving flux from Equation (19). The ice margin is capable of moving forward at a velocity, $\nu_{\mathrm{im}}$, which is the difference between the flow velocity of the ice and the minimum calving velocity at the moraine shoal; that is,

$$
\nu_{\mathrm{im}}=\frac{q_{\mathrm{i}}}{h_{\mathrm{is}}}-\frac{q_{\mathrm{c}}}{h_{\mathrm{is}}} .
$$

If $\nu_{\mathrm{im}}>\nu_{\mathrm{s}}$, the shoal-advance rate, then the excess ice begins to over-top the shoal but calves immediately, and the moraine shoal and calving front move forward together at the rate $\nu_{\mathrm{s}}$. If $\nu_{\mathrm{im}}<\nu_{\mathrm{s}}$, then the ice loses contact with its shoal, the water depth and calving rate increase, and the calving front migrates at the velocity $\nu_{\text {im }}$ with $h_{\mathrm{s}}=0$, and retreats from the shoal rapidly.

Typical ice fluxes, $q_{\text {io }}$, are approximately $10^{5} \mathrm{~m}^{3} \mathrm{a}^{-1}$ $\mathrm{m}^{-1}$ (ice a few hundred meters thick moving a few hundred meters per year) and typical surface balances are -1 to $-10 \mathrm{~m} \mathrm{a}^{-1}$, so the ice must advance kilometers or tens of kilometers for surface melting to remove a significant fraction of $q_{\text {io. }}$. Assuming that the climatic parameters $q_{\text {io }}$ and $\dot{b}$ are constant (and that sea level is also constant), inspection of Equations (15) to (17) reveals:

(i) on a horizontal bed, if sediment supply is large compared to recycling $\left(q_{\mathrm{b}} \gg q_{\mathrm{r}}\right)$ then the ratio of the rates of water-depth decrease to moraine-shoal advance is $\tan \phi_{u}$ or approximately $10 \%$. But, because typical water depths are roughly $100 \mathrm{~m}$ and advance distances long enough to affect ice flux significantly through surface ablation are about $10 \mathrm{~km}$, the shoal builds to sea level before significant advance occurs. Marginal retreat unrelated to climate is unlikely. This situation cannot exist on calving tidewater glaciers that are observed to fluctuate over large horizontal distances. Rather, on such fluctuating tidewater glaciers, sediment recycling across the shoal must be rapid compared to sediment supply to the shoal;

(ii) on a horizontal bed, if sediment supply is small compared to recycling $\left(q_{\mathrm{b}} \ll q_{\mathrm{r}}\right)$, then the moraine shoal migrates forward rapidly, extending the ablation zone and reducing ice flux to the ice front. However, the moraine shoal does not grow rapidly, so calving is not reduced rapidly. The glacier may advance until ice flux is less than calving flux, triggering retreat without climatic forcing (but if sediment supply is zero, the glacier never advances from its most retreated position); 


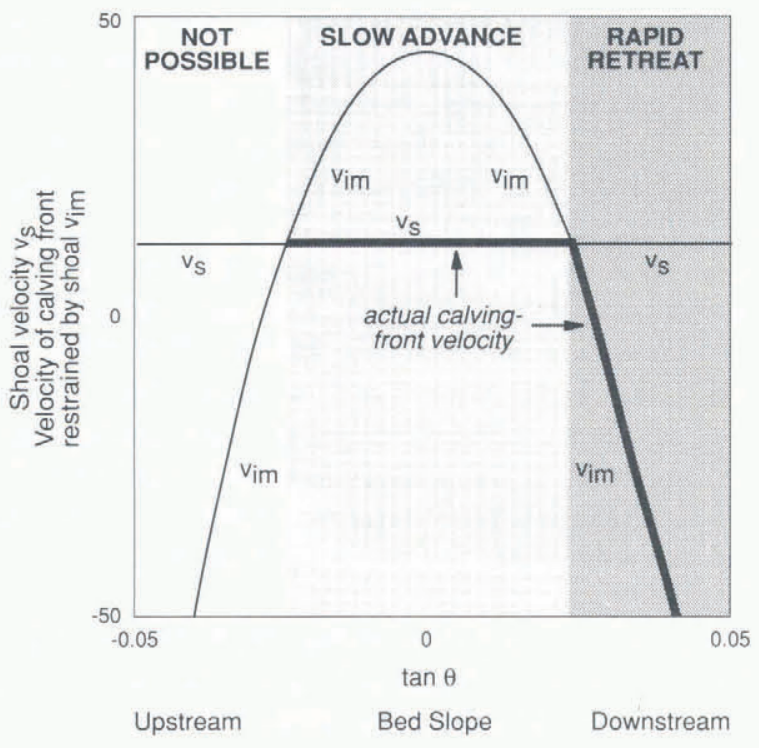

Fig. 5. Modeled velocity of calving front as a function of bed slope, $\theta$, calculated using values in the table. The shoal advances at $\nu_{s}$, and the calving front can advance as rapidly as $\nu_{i m}$ if calving occurs at the minimum rate. The calving front actually advances at the lesser of $\nu_{s}$ and $\nu_{i m}$, shown by the heavy line. Where $\nu_{\text {im }}<\nu_{s}$, the ice will lose contact with the shoal, triggering retreat at around $1000 \mathrm{ma}^{-1}$ (marked "Rapid Retreat"). If the bedrock slopes sufficiently steeply up-glacier, then the calving front could not have passed through the deeper water there to reach the assumed position (marked "Not Possible"). The variables and values assumed in calculating Figure 5 are given in Table 1.

(iii) if the glacier advances over a bed that shallows along flow $(\theta<0)$, then over time the water depth at the ice front will decrease, calving will decrease, and retreat unrelated to climate will be unlikely. Instead, the shoal will build above sea level, halting calving, and advance will occur until ablation removes the entire ice flux (Fig. 5);

(iv) if the glacier advances over a bed that deepens along flow $(\theta>0)$ then the water depth may increase with time (if forward migration causes deepening faster than new supply builds up the shoal). This will increase calving, and retreat will become likely (Fig. 5).

In the second and fourth possibilities, the ice-marginal position can undergo catastrophic retreat with no climatic forcing. In the first and third possibilities, icemarginal fluctuations are more likely to record climatic forcing. Interactions of bed slope, ice and sediment supply, and recycling can create a wide range of behavior within these end members. In particular, a glacier can advance down a sloping bed if new sediment supply, $q_{\mathrm{b}}$ is a significant fraction of the recycling rate, $q_{\mathrm{r}}$, so the common observation that temperate tidewater glaciers advance through overdeepenings is consistent with this model.
Table 1. Variables used, and values assumed in calculating example in Figure 5.

$\dot{b}$

$c, d \quad$ computational intermediates, $\mathrm{m}$

$h_{\mathrm{b}} \quad$ deforming-bed thickness, $\mathrm{m}$

$h_{\text {bo }}$ deforming-bed thickness up-glacier of shoal, $m$

$h_{\mathrm{b} \max }$ deforming-bed thickness on shoal, $\mathrm{m}$

$h_{\text {ia }} \quad$ ice-cliff height above water at calving front, $\mathrm{m}, 130$

$h_{\text {is }} \quad$ total ice thickness at calving front, $\mathrm{m}$

$h_{\mathrm{s}} \quad$ shoal height, from bedrock to peak, $\mathrm{m}$

$h_{\text {wo }} \quad$ water depth at calving front without shoal, $\mathrm{m}, 170$

$h_{\mathrm{ws}} \quad$ water depth over shoal peak, $\mathrm{m}$

$K \quad$ calving constant, 27

$l_{\mathrm{a}} \quad$ glacier length from most retreated position, $\mathrm{m}, 10^{4}$

$l_{\mathrm{b}}, l_{\mathrm{r}}, l_{\mathrm{s}}$ computational intermediates, $\mathrm{m}$

$m, n \quad$ computational intermediates, $\mathrm{m}$

$q_{\mathrm{b}} \quad$ sediment flux to shoal, $\mathrm{m}^{3} \mathrm{a}^{-1} \mathrm{~m}^{-1}, 100$

$q_{\mathrm{c}} \quad$ minimum ice-calving flux, $\mathrm{m}^{3} \mathrm{a}^{-1} \mathrm{~m}^{-1}$

$q_{\mathrm{i}} \quad$ ice flux at ice front, $\mathrm{m}^{3} \mathrm{a}^{-1} \mathrm{~m}^{-1}$

$q_{\text {io }} \quad$ ice flux at most retreated ice position, $\mathrm{m}^{3} \mathrm{a}^{-1} \mathrm{~m}^{-1}$

$q_{\mathrm{r}} \quad$ recycled sediment flux across shoal, $\mathrm{m}^{3} \mathrm{a}^{-1} \mathrm{~m}^{-1}, 2000$

$q_{\mathrm{s}} \quad$ sediment flux in deforming bed, $\mathrm{m}^{3} \mathrm{a}^{-1} \mathrm{~m}^{-1}$

$t \quad$ time over which shoal has been accumulating, a, 1000

$u_{\mathrm{i}} \quad$ velocity of sediment top, $\mathrm{m} \mathrm{a}^{-1}$

$\nu_{\mathrm{im}} \quad$ maximum possible ice-margin advance rate, $\mathrm{m} \mathrm{a}^{-1}$

$\nu_{\mathrm{s}} \quad$ shoal-advance rate, $\mathrm{m} \mathrm{a}^{-1}$

$\alpha \quad$ coefficient for variation in sediment velocity with depth

$\theta \quad$ down-glacier slope of bedrock

$\phi_{\mathrm{d}} \quad$ slope of down-glacier side of shoal, $\tan \phi_{\mathrm{d}}=0.2$

$\phi_{\mathrm{u}} \quad$ slope of up-glacier side of shoal, $\tan \phi_{\mathrm{u}}=0.2$

\section{DISCUSSION AND CONCLUSIONS}

The model here suffers from a number of weaknesses and oversimplifications, including: one dimensionality, lack of ice dynamics, use of smooth, homogeneous bedrock and constant shoal angles, and lack of explicit treatment of stream transport. I thus cannot model the possible effects of changes in valley width, interference by bedrock islands, icebergs backing up behind a shoal and slowing incipient retreat from the shoal, changes in longitudinal stresses in the ice, changes in the balance between stream and deforming-bed transport and their effect on repose angles of shoals, and ice-front sedimentation from marginal streams (e.g. Post, 1975; Meier and Post, 1987; Andrews, 1990). Many of these features could be added to the model, but the lack of a quantitative understanding of subglacial stream transport prevents a quantitative understanding of moraine-shoal processes.

Despite these and other objections, however, it seems hard to avoid the observation that glaciers with thawed beds often advance over their own sediments, that those sediments are unlithified and thus easily eroded, and that this leads to conveyor-belt sediment recycling and ice advance. This should be true for wet-bedded cold (Alley and others, 1989) or temperate glaciers entering bodies of water and for glaciers ending on land, and should af- 
fect the dynamics of all of these glaciers. If a glacier entering a water body requires restraint from sediments to maintain an advanced ice-front position, then it seems likely that the resulting basal shear stress on these sediments will cause continued recycling and advance. Under some conditions, this should lead the ice front into a position where calving flux exceeds ice flux, triggering catastrophic retreat. The marginal fluctuations of such a glacier could then represent either climatic forcing or the internal sediment-ice processes. Further study is warranted before any attempt is made to reconstruct climatic forcing from observed fluctuations of such glaciers.

\section{ACKNOWLEDGEMENTS}

I thank Mark Meier and two anonymous reviewers for helpful information and suggestions. This research was funded in part by the U.S. National Science Foundation under grants DPP-8716016 and DPP-8915995.

\section{REFERENCES}

Alley, R.B. 1989. Water-pressure coupling of sliding and bed deformation: II. Velocity-depth profiles. F. Glaciol., 35(119), 119-129.

Alley, R.B., D.D. Blankenship, S.T. Rooney, and C.R. Bentley. 1989. Sedimentation beneath ice shelves - the view from Ice Stream B. Mar. Geol., 85(2/4), 101-120.

Anderson, J.B. and B.F. Molnia. 1989. Glacial-marine sedimentation. Washington, DC, American Geophysical Union. (Short Course in Geology, Vol. 9.)
Andrews, J.T. 1990. Fjord to deep sea sediment transfers along the northeastern Canadian continental margin: models and data. Géogr. Phys. Quat., 44(1), 55-70.

Bindschadler, R. 1983. The importance of pressurized subglacial water in separation and sliding at the glacier bed. F. Glaciol., 29(101), 3-19.

Boulton, G.S. and R.C.A. Hindmarsh. 1987. Sediment deformation beneath glaciers: rheology and geological consequences. 7. Geophys. Res., 92(B9), 9059-9082.

Brown, C.S., M.F. Meier, and A. Post. 1982. Calving speed of Alaska tidewater glaciers, with application to Columbia Glacier. U.S. Geol. Surv. Prof. Pap. 1258-C.

Fahnestock, M. and N. Humphrey. 1988. Borehole water level measurements, Columbia Glacier, AK. Ice, 86, 2526.

MacClintock, P. and A. Dreimanis. 1964. Reorientation of till fabric by overriding glacier in the St. Lawrence valley. Am. J. Sci., 262(1), 133-142.

Meier, M.F. 1989. Relation between water input, basal water pressure, and sliding of Columbia Glacier, Alaska, U.S.A. (Abstract.) Ann. Glaciol., 12, 214-215.

Meier, M.F. and A. Post. 1987. Fast tidewater glaciers. F. Geophys. Res., 92(B9), 9051-9058.

Post, A. 1975. Preliminary hydrology and historic terminal changes of Columbia Glacier, Alaska. U.S. Geol. Surv. Hydrol. Invest. Atlas, map HA-559.

Powell, R.D. 1984. Glacimarine processes and inductive lithofacies modelling of ice shelf and tidewater glacier sediments based on Quaternary examples. Mar. Geol., $\mathbf{5 7}(1 / 4), 1-52$.

The accuracy of references in the text and in this list is the responsibility of the author, to whom queries should be addressed. 